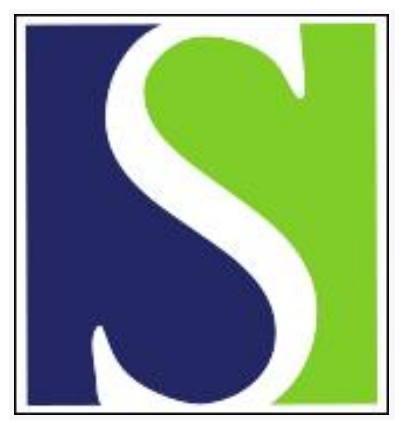

Scand J Work Environ Health 2008;34(3):179-188

https://doi.org/10.5271/sjweh.1227

Issue date: 30 Jun 2008

Health-related effects of worksite interventions involving physical exercise and reduced workhours

by von Thiele Schwarz U, Lindfors P, Lundberg U

Affiliation: Department of Psychology, Stockholm University, SE-106 91 Stockholm, Sweden. uvt@psychology.su.se

Refers to the following texts of the Journal: 2003;29(1):1-4 1997;23

suppl 1:49-57 2002;28(3):141-157 2003;29(1):27-34

The following articles refer to this text: 2017;43(2):109-116;

2018;44(2):113-133

Key terms: biomarker; cluster randomization; health promotion; health protection initiative; health-related effect; MSD; musculoskeletal disorder; physical activity; physical exercise; reduced workhours; upper-extremity disorder; woman; work ability; workhours; worksite intervention

This article in PubMed: www.ncbi.nlm.nih.gov/pubmed/18728907

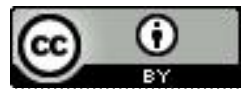




\title{
Health-related effects of worksite interventions involving physical exercise and reduced workhours
}

\author{
by Ulrica von Thiele Schwarz, MSc, ${ }^{1}$ Petra Lindfors, PhD, ${ }^{2}$ Ulf Lundberg, PhD ${ }^{2}$
}

\begin{abstract}
von Thiele Schwarz U, Lindfors P, Lundberg U. Health-related effects of worksite interventions involving physical exercise and reduced workhours. Scand J Work Environ Health. 2008;34(3):179-188.

Objectives This study examined the health-related effects of two worksite interventions, physical exercise and reduced workhours, on women employed in dentistry.

Methods Six workplaces were randomized to one of the following three conditions: (i) 2.5 hours of weekly, mandatory physical exercise of middle-to-high intensity to be performed during workhours (N=62), (ii) a reduction of full-time weekly workhours from 40 to 37.5 hours ( $=50$ ), and (iii) reference. In all, 177 women participated. Biomarkers and self-ratings in questionnaires were obtained before the intervention $\left(\mathrm{T}_{1}\right)$, and six $\left(\mathrm{T}_{2}\right)$ and 12 months $\left(\mathrm{T}_{3}\right)$ after the intervention.

Results The results showed increased levels of physical activity and exercise in all of the groups, the level of physical exercise being significantly greater in the physical exercise group. Repeated-measures analyses of variance using data from $\mathrm{T}_{1}$ and $\mathrm{T}_{3}$ for biological measures and all three time points for self-ratings produced significant interaction effects for glucose, waist-to-hip ratio, and work ability and clear trends for general symptoms and upper-extremity disorders. Posthoc analyses showed that the results of the health-related measures differed between the interventions, decreased glucose and upper-extremity disorders in the exercise group, and increased high-density lipoprotein and waist-to-hip ratio among those working reduced hours.

Conclusions These results show that the two interventions had small and varied effects on biomarkers and self-reports of different aspects of health among women. It is suggested that interventions involving a modest reduction in workhours seem to be more effective if these hours are used for physical exercise.
\end{abstract}

Key terms biomarker, cluster randomization, health promotion, health protection initiative, musculoskeletal disorder, physical activity, upper-extremity disorder, woman, work ability.

Research has shown that worksite health interventions involving physical activity effectively increase levels of physical activity (1), physical fitness, and perceived health status and prevent an early decline of work ability (2). Moreover, such interventions have been found to reduce headache and neck pain (3) and the risk of developing musculoskeletal disorders (4) and to increase levels of subjective physical well-being (5). However, reviews and meta-analyses present inconclusive findings (6). For instance, effect sizes for worksite physical-activity interventions have been small (mean $\mathrm{r}=0.11$ ), although these results have been explained with reference to the poor quality of the research in the field $(6,7)$.

Over the last decade, several worksite health-promotion initiatives involving reduced workhours have been carried out within the public service and health care sectors in the Nordic countries (8-13). These initiatives include reducing the number of workhours per day or per week (eg, from 40 to 30 hours of weekly workhours for all employees within an organization). So far, reducing workhours from 8 hours/day to 6 hours/day has been related to positive social effects and decreased work-family conflict, particularly for employees with children $(8,11)$. With regard to health effects, the 6 hour workday has been found to be associated with a considerable reduction of pain in the neck-shoulder area in employees within the public care sector (10). This finding was confirmed in a recent study investigating health effects of 6-hour workdays. In addition, this study showed decreased stress levels among the participants (13). However, evaluations of different types of reduced workhours have only produced minor effects on other

1 AB Previa and Department of Psychology, Stockholm University, Stockholm, Sweden.

2 Department of Psychology, Stockholm University and CHESS, Center for Health Equity Studies, Stockholm University/Karolinska Institutet, Stockholm, Sweden.

Reprint requests to: Ulrica von Thiele Schwarz, Department of Psychology, Stockholm University, SE-106 91 Stockholm, Sweden. [E-mail: uvt@psychology.su.se] 
health-related factors, such as fatigue, disturbed sleep, and physiological factors $(9,11,13)$.

The understanding of how reduced workhours can promote health is still poor. In addition to reducing the quantitative load from paid work, at least three other ways in which reduced workhours may promote health have been suggested $(9,11,12)$. Reduced workhours may reduce interference between different life domains, increase time for recovery from work stress, and increase the time spent on health-promoting leisure-time activities, such as physical activity. Even though these health-promoting effects have been suggested, few studies have included an assessment of the balance between different life domains, recovery from work stress, and physical activity.

Both research on physical activity interventions at work and evaluations of reduced workhours have been criticized for a lack of methodological rigor, such as neglecting to include reference groups $(9,12,14)$. In addition, studies of worksite physical-activity interventions often suffer from low participation rates and are biased due to self-selection $(15,16)$, while reduced workhours seldom include systematic longitudinal measurements at several points in time $(9,12)$. Moreover, many existing studies often lack adequate measures reflecting different aspects of health $(9,12,14)$, such as self-ratings and biomarkers. Worksite interventions have also been criticized for targeting a selected group of already healthy, highly educated white-collar workers, predominantly men, within large organizations in Western countries $(7,14,17)$.

Our present study was meant to investigate the health-related effects of physical exercise and reduced workhours among women employed in dentistry within the public health care sector. Dentistry involves high stress, characterized by physical and psychological demands, and also involves such factors as output of muscular strength and time pressure that are known to have negative effects on work ability $(18,19)$. In addition, musculoskeletal disorders, particularly in the upper extremities, are common (20). This combination of a stressful work situation and a high prevalence of musculoskeletal disorders calls for the identification of effective interventions targeting this risk group. Drawing on previous research $(1,2,4,8,10,11,13)$, we hypothesized that taking part in a mandatory, workbased physical-exercise intervention, involving physical activity of medium-to-high intensity, or working fewer hours per week would improve health. These health improvements were expected to be reflected in biomarkers and self-ratings of health, symptoms, and work ability in a comparison with a reference group. Second, we hypothesized that the levels of physical activity would increase in the physical-exercise group, while participants in the reduced workhours group, apart from showing an increase in physical activity, would experience reduced work-home interference and a better recovery from work stress.

\section{Study population and methods}

\section{Design}

Female employees from six workplaces in a large public dental health care organization in Stockholm, Sweden, participated in the study. To ensure comparability, all workplaces in the organization were ranked according to their registered sickness absence levels, and three workplaces with a high level of sickness absence and three with low levels, each employing at least 25 persons, were selected. Workplaces with a high and a low sickness absence were matched according to the number of employees. This matching resulted in three pairs that were randomly allocated to one of the following three groups: (i) physical-exercise group (PE), (ii) reduced-workhours group (RWH), and (iii) reference group (R). At the two workplaces acting as reference, no intervention was carried out; at the two workplaces engaging in physical exercise, 2.5 hours of weekly workhours were allocated to mandatory physical exercise on two different days; at the two workplaces implementing reduced workhours, full-time weekly hours were reduced from 40 hours/week to 37.5 hours/week. For the employees working part-time, the time allocated to physical exercise and the reduction of workhours was set to 2 hours for those working 30-39 hours/week (39\% of the employees), to 1.5 hours for those who worked 21-29 hours/week (14\%), and to 1 hour for those who worked less than 20 hours (2\%). All of the employees in the intervention groups retained their salaries. No additional personnel were employed, and all of the workplaces were expected to deliver full services throughout the study period.

The mandatory physical activity was to involve exercise of medium-to-high intensity, corresponding to $55 \%$ to $89 \%$ of the person's maximum heart rate. For the participants, this was operationalized as vigorous activity of such intensity that it would be difficult keeping up a conversation while exercising and would make them sweat so that they would have to shower. The employees were free to choose any type of physical exercise as long as the intensity criterion was met. All of the employees recorded, in writing, the type of activity and the duration of each exercise session; these written reports were checked weekly by a specifically assigned employee.

The physical-exercise group included 62 women, the reduced-workhours group had 50 women, and 65 employees served as referents. In all three groups, 
biomarkers and self-ratings in questionnaires were obtained before the intervention $\left(\mathrm{T}_{1}\right)$, and 6 months $\left(\mathrm{T}_{2}\right)$ and 12 months $\left(\mathrm{T}_{3}\right)$ after the intervention to allow for analyses of the changes between the different points in time (21). The time lag between measurements was based on experiences from previous studies $(8,10)$. However, because there are well-known seasonal variations in biomarkers and blood pressure (22-25), only data from $\mathrm{T}_{1}$ and $\mathrm{T}_{3}$ (collected during the same season) have been considered in the analyses of these measures. The study was approved by the Central Ethical Review Board and in accordance with ethical guidelines. All of the participants for whom biomarker values deviated from the expected range and needed medical consideration were immediately informed. When the project was completed, all of the participants were informed about the overall results of the study.

\section{Study population}

In all, 197 women employed at the six workplaces were invited to take part in the study. Of the women invited, 195 volunteered to participate. The dropout was $9.2 \%$ (3.6\% after the first phase and 5.6\% after the second phase). The dropouts were due to a change in jobs $(4.6 \%)$, parental leave $(2.6 \%)$, long-term sick leave or disability pension $(1.2 \%)$, while $0.8 \%$ declined to participate in the follow-ups. Of the 177 women who participated in all three phases, blood samples were missing for six women, disallowing the analysis of biomarkers. In addition, extreme values from three diabetics and six pregnant women were excluded. Altogether, the statistical analyses of biomarkers included data from 162 women.

The mean age for the whole sample was 46.6 years [46.7 (SD 10.5) for the physical-exercise group, 46.6 (SD 10.6) for the reduced workhours group, and 46.6 (SD 11.2) for the reference group]. Most (70.1\%) of the women were married or living with a partner $(66.1 \%$ of the physical-exercise group, $80.0 \%$ of the reducedworkhours group, $66.2 \%$ of the reference group), and most $(57.5 \%)$ had children living at home $(55.9 \%$ of the physical-exercise group, $62.0 \%$ of the reduced-workhours group, $55.4 \%$ of the reference group). With respect to education, $44.8 \%$ of the women had completed upper secondary school (44.1\% of the physical-exercise group, $42.0 \%$ of the reduced-workhours group, $47.7 \%$ of the reference group), while $40.8 \%$ had a university degree $(39.0 \%$ of the physical-exercise group, $42.0 \%$ of the reduced-workhours group, $41.5 \%$ of the reference group). The mean worktime was 34.2 hours/week [33.7 (SD 7.1) for the physical-exercise group, 34.5 (SD 6.2) for the reduced-workhours group, 34.4 (SD 7.0) for the reference group]. The mean tenure was 16.3 years for the entire group [16.9 (SD 11.1) for the physical-exercise group, 16.2 (SD 10.9) for the reduced-workhours group, 15.9 (SD 11.6) for the reference group].

\section{Procedure}

Prior to each of the three phases, the participants were given detailed oral and written information about the project, ethical issues, and the procedures for the measurements (questionnaire and a health checkup). The questionnaire was completed at home and returned to the licensed nurse, who performed the health checkups. The checkups took place during the morning (0730 to 1000) in a secluded room at the workplace. All of the participants were instructed to refrain from eating for 12 hours prior to the checkup. In addition, they were asked to rise at least 2 hours before the checkup and, in the meantime, refrain from consuming coffee and nicotine and to avoid intense mental or physical activity.

All of the health checkups followed a standardized protocol and involved the sampling of blood and measurements of the waist-to-hip ratio, blood pressure, and heart rate. Blood samples were drawn to determine blood lipids, including total cholesterol, triglycerides, highdensity lipoproteins (HDL) and low-density lipoproteins (LDL), the LDL-to-HDL ratio, dehydroepiandesterone sulphate (DHEAS), glucose, glycosylated hemoglobin $\left(\mathrm{HbA}_{1 \mathrm{C}}\right)$, and prolactin. In all, 25 milliliters of venous blood was sampled and left to coagulate for a minimum of 30 minutes and a maximum of 120 minutes before being centrifuged at room temperature (15 minutes, $1000 \times g$ ) and transported to a commercial laboratory for chemical analysis. Waist circumference was measured at the narrowest point between the rib and iliac crest, and hip circumference was determined at the maximal buttocks; these measures were used to calculate the waist-to-hip ratio. A semiautomatic device (Boso, Bosch + , Sohn, Germany) was used to measure systolic blood pressure, diastolic blood pressure, and heart rate. The measurements were performed after an initial 5-minute resting period, and repeated three times with 5-minute periods of rest between the measurements. The mean value of the last two recordings was computed and used in the statistical analyses.

\section{Questionnaire}

In addition to demographic factors (gender, age, marital status, children, education, and current occupation), the questionnaire also included measures of physical activity and health-related factors.

Physical activity. The level of physical activity was assessed by the following two items, which were based on general recommendations (26): overall physical activity (exemplified in the questionnaire as walking, biking, 
household chores, gardening, playing with children) and physical exercise (exemplified as aerobics, running, and swimming). The respondents were asked to rate how much time they spent on the average during a normal week on physical activity and physical exercise. The ratings were marked on a 4-point scale ranging from "less than 1 hour a week" or "no activity at all" (1) to "5-6 hours a week" or "more than 1 hour a day" (4).

Recovery. Recovery from work stress $(27,28)$ included both fatigue ( 4 items) and recovery ( 4 items). All of the items were rated on a 5-point scale ranging from "never" (1) to "very often" (5). To compute the scores for fatigue and recovery, sum scores were calculated and then divided by the number of items, allowing a range from 1 to 5 for each of the measures. High scores indicated high fatigue and poor recovery. The internal consistency (Cronbach's alpha) was 0.71 for fatigue and 0.82 for recovery.

Interference between work and home. The work-home interference, that is, whether worklife interferes with home life, was assessed by two items (29). Both items were rated on a 7-point scale ranging from "very seldom" (1) to "very often" (7), and the ratings were summed for work-home interference. The sum scores were then divided by the number of items, allowing a range from 1 to 7 , the high scores indicating high interference. The internal consistency for this measure was 0.71 .

Self-rated health. Self-rated health was assessed using a single-item question that asked the respondents to rate their current health status as compared with that of other persons of the same age. The ratings were marked on a 5-point scale, ranging from "very good" (1) to "very poor" (5) (30).

Work ability. Work ability was measured using a single item $(31,32)$. The respondents were asked to rate their current work ability as compared with their work ability at its best on a 10-point scale ranging from "completely lacking work ability" (1) to "work ability at its best" (10).

General symptoms. General symptoms were measured using a modified version of the general Nordic questionnaire (QPSNordic) (32) and covered nine common symptoms (heartburn, nausea, stomachache, palpitations, coughs, colds, headaches, fatigue, and sleep disturbances). The respondents were asked to indicate whether they had experienced a symptom during the past 6 months. Sum scores were computed and ranged from 0 to 9 , high scores indicating more symptoms.

Musculoskeletal symptoms. Musculoskeletal symptoms in the upper extremities (neck, shoulder, and hand-wrist areas) were measured using the standardized Nordic questionnaire (33). For all of the items, the respondents were asked to indicate whether they had experienced symptoms or pain during the past 6 months. Sum scores were computed and ranged from 0 to 3 , high scores indicating more symptoms.

\section{Statistical analyses}

Before the main analyses were performed, internal consistency coefficients (Cronbach's alpha) were computed for all of the measures that included two items or more. To examine the effects of the interventions on the outcome measures, we tested interaction and overall time effects using repeated-measures analyses of variance (ANOVA), considering three time points $\left(\mathrm{T}_{1}, \mathrm{~T}_{2}\right.$ and $\left.\mathrm{T}_{3}\right)$ for the self-ratings and two time points $\left(\mathrm{T}_{1}\right.$ and $\left.\mathrm{T}_{3}\right)$ for the biomarkers and cardiovascular measures. The significant main effects of the time and interaction effects were followed by posthoc tests. Due to missing data, the sample size and degrees of freedom varied slightly between the analyses.

\section{Results}

\section{Physical activity}

Figure 1 presents the mean levels of physical exercise in the three groups at the three time points. There was a significant increase in physical exercise in all three groups over time $(\mathrm{P}<0.001$ for the physical-exercise group, $\mathrm{P}<0.001$ for the reduced-workhours group, $\mathrm{P}<0.001$ for the reference group). The time $\times$ group interaction effect $[\mathrm{F}(4,310)=82.33, \mathrm{P}<0.001]$ with posthoc tests showed that the increase in the physical-exercise group was significantly greater than in the other two groups (physical-exercise versus reduced-workhours: $\mathrm{P}=0.024$; physical-exercise versus reference: $\mathrm{P}<0.001)$. The mean levels of physical activity (of low intensity) increased as well, starting at a level corresponding to approximately $3-4$ hours of weekly physical activity $[\mathrm{F}(2,158)=16.54$, $\mathrm{P}<0.001]$. The time $\times$ group effect approached significance $[\mathrm{F}(4,318)=2.13, \mathrm{P}=0.077]$.

\section{Biomarkers}

Table 1 presents descriptive statistics (means and standard deviations) and 95\% confidence intervals and the results from repeated ANOVA for the biological measures. For the blood lipids, neuroendocrine markers, and cardiovascular measures, no significant time $\times$ group effects were found. However, there was a time effect that showed increasing levels of blood lipids from $\mathrm{T}_{1}$ to $\mathrm{T}_{3}$ for all of the blood lipids but the LDL-to-HDL ratio. 


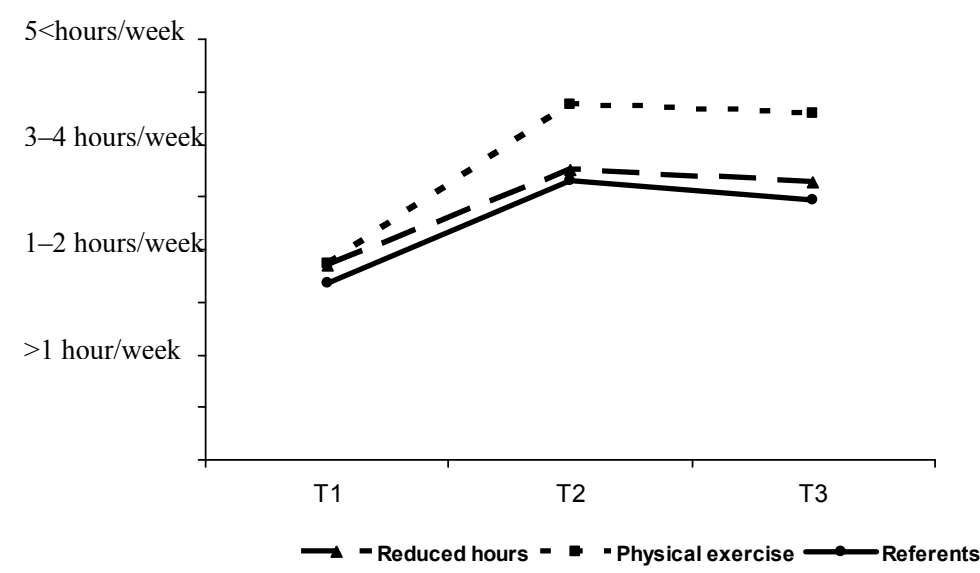

Figure 1. Level of self-rated physical exercise before $\left(T_{1}\right)$, after 6 months $\left(T_{2}\right)$, and after 12 months $\left(T_{3}\right)$ of participation in interventions involving physical exercise or reduced workhours.
The posthoc analyses showed increasing levels of all of the blood lipids in the reference group $[F(1,60)=19.01$, $\mathrm{P}<0.001$, for total cholesterol; $\mathrm{F}(1,60)=6.18, \mathrm{P}=0.016$, for triglycerides; $\mathrm{F}(1,60)=9.31, \mathrm{P}=0.003$, for $\mathrm{HDL}$; $\mathrm{F}(1,60)=19.01, \mathrm{P}<0.001$, for LDL]. In the reducedworkhours group, total cholesterol and HDL had increased significantly $[\mathrm{F}(1,40)=5.98, \mathrm{P}=0.019$, for total cholesterol; $\mathrm{F}(1,40)=12.35, \mathrm{P}=0.016$, for HDL], while only total cholesterol had increased significantly in the physical-exercise group $\left[\mathrm{F}_{\mathrm{TC}}(1,57)=5.92, \mathrm{P}=0.018\right]$.

Significant effects were also found for the metabolic measures. For glucose, there was a significant time $\times$ group effect $(\mathrm{P}=0.04)$, the posthoc analyses showing significant decreases in the physical-exercise group only $[\mathrm{F}(1,57)=4.64, \mathrm{P}=0.036]$. A significant interaction effect emerged for the waist-to-hip ratio $(\mathrm{P}=0.02)$, the posthoc analyses revealing that the waist-to-hip ratio increased in the reduced-workhours group $[\mathrm{F}(1,42)=11.7, \mathrm{P}<0.001]$. For $\mathrm{HbA}_{1 \mathrm{c}}$, there was an effect of time showing decreasing levels of $\mathrm{HbA}_{1 \mathrm{c}}$ $(\mathrm{P}=0.03)$, but no interaction effect.

\section{Self-reports}

Table 2 presents descriptive statistics (means and standard deviations) and 95\% confidence intervals and the results from the repeated ANOVA for the self-report measures. No significant effects emerged for self-rated health, work-home interference, lack of recovery, or fatigue. For work ability, the time $\times$ group effect $[\mathrm{F}$ (4, $314)=3.35, P=0.01]$ was significant. The posthoc analyses showed that work ability deceased in the reference group $[\mathrm{F}(2,116)=5.58, \mathrm{P}=0.005]$, while there were no significant changes in the physical-exercise and the reduced-workhours groups. Similar results were found for general symptoms, namely, the number of symptoms increased in the reference group $[\mathrm{F}(2,118)=5.31$, $\mathrm{P}=0.006]$. However, the time $\times$ group effect did not reach significance $[\mathrm{F}(4,316)=2.26, \mathrm{P}=0.063]$. For upper-extremity disorders, the time $\times$ group effect ap- proached significance $[\mathrm{F}(4,314)=2.26, \mathrm{P}=0.062]$, sug gesting significant decreases in upper-extremity disorders in the physical-exercise group only $[\mathrm{F}(2,114)=4.64$, $\mathrm{P}=0.012]$.

\section{Discussion}

In line with the initial hypotheses, the levels of physical activity (low-intensity physical activity and physical exercise) increased in both intervention groups, but also in the reference group. However, the increase in physical exercise was greater in the physical-exercise group and in line with previous research showing that worksitebased interventions may be effective in increasing the levels of physical activity (1).

\section{Effects of the interventions}

In the tests of the effects of the three conditions on the outcomes, significant interaction effects emerged for glucose, waist-to-hip ratio, and work ability. For general symptoms and upper-extremity disorders, the interaction effects approached significance. In other words, most of the interaction effects failed to reach significance. Apart from many of the effects being small, the lack of interaction effects may have resulted from the different conditions being too similar. First, both intervention groups included a reduction of workhours, although work was replaced by physical activity in one group but not in the other. Second, even though the physical-exercise group exhibited the greatest increase in physical activity and a greater increase in terms of physical exercise, the levels of physical activity and physical exercise increased in all three groups. Third, the mean baseline levels of self-rated physical activity were relatively high, corresponding to 3-4 hours of weekly low-intensity physical activity, which may have limited the variability and contributed to ceiling effects in terms of health improvement. 
Table 1. Descriptive statistics (means and standard deviations) and $95 \%$ confidence intervals $(95 \% \mathrm{Cl}$ ) for the biomarkers for the two intervention groups and the reference group at baseline and after 12 months and results from repeated analyses of variance reporting time $(T)$ effects, interaction $(\mathrm{I})$ effects and exact P-values. (HDL = high-density lipoprotein, $L D L=$ low-density lipoprotein, DHEAS = dehydroepiandesterone sulfate, $\mathrm{HbA} 1 \mathrm{c}=$ glycosylated hemoglobin)

\begin{tabular}{|c|c|c|c|c|c|c|c|c|c|}
\hline \multirow[t]{2}{*}{ Biomarker } & \multirow[t]{2}{*}{$\mathrm{N}$} & \multicolumn{3}{|c|}{ Before } & \multicolumn{3}{|c|}{12 months } & \multirow[t]{2}{*}{ F-value } & \multirow[t]{2}{*}{ P-value } \\
\hline & & Mean & SD & $95 \% \mathrm{Cl}$ & Mean & SD & $95 \% \mathrm{Cl}$ & & \\
\hline \multicolumn{10}{|l|}{ Blood lipids } \\
\hline \multicolumn{10}{|l|}{ Total cholesterol (mmol/l) } \\
\hline Exercise group & 58 & 5.08 & 0.89 & $4.88-5.34$ & 5.23 & 0.96 & $5.01-5.52$ & $\mathrm{~T}: 27.1$ & 0.001 \\
\hline Reduced hours group & 41 & 5.16 & 0.93 & $4.86-5.43$ & 5.33 & 0.99 & $4.99-5.59$ & $\mathrm{I}: 0.78$ & 0.46 \\
\hline Reference group & 60 & 5.29 & 1.04 & $5.02-5.55$ & 5.54 & 1.09 & $5.25-5.81$ & & \\
\hline \multicolumn{10}{|l|}{ Triglycerides (mmol/l) } \\
\hline Exercise group & 58 & 1.01 & 0.48 & $0.88-1.14$ & 1.08 & 0.72 & $0.91-1.31$ & $\mathrm{~T}: 8.30$ & 0.001 \\
\hline Reduced hours group & 41 & 0.97 & 0.60 & $0.79-1.15$ & 1.11 & 0.91 & $0.87-1.44$ & I: 0.34 & 0.71 \\
\hline Reference group & 60 & 0.99 & 0.73 & $0.80-1.17$ & 1.13 & 1.05 & $0.86-1.30$ & & \\
\hline \multicolumn{10}{|l|}{$\mathrm{HDL}(\mathrm{mmol} / \mathrm{l})$} \\
\hline Exercise group & 58 & 1.86 & 0.41 & $1.75-1.96$ & 1.89 & 0.41 & $1.78-1.99$ & $\mathrm{~T}: 19.6$ & 0.001 \\
\hline Reduced hours group & 41 & 1.80 & 0.33 & $1.69-1.90$ & 1.91 & 0.41 & $1.78-2.04$ & I: 1.74 & 0.18 \\
\hline Reference group & 60 & 1.82 & 0.30 & $1.75-1.90$ & 1.90 & 0.37 & $1.81-2.00$ & & \\
\hline \multicolumn{10}{|l|}{$\operatorname{LDL}(\mathrm{mmol} / \mathrm{l})$} \\
\hline Exercise group & 56 & 2.75 & 0.71 & $2.59-2.98$ & 2.82 & 0.75 & $2.66-3.05$ & $\mathrm{~T}: 5.41$ & 0.02 \\
\hline Reduced hours group & 40 & 2.89 & 0.68 & $2.67-3.08$ & 2.91 & 0.70 & $2.64-3.06$ & I: 0.81 & 0.45 \\
\hline Reference group & 59 & 3.02 & 0.89 & $2.78-3.24$ & 3.14 & 0.91 & $2.89-3.36$ & & \\
\hline \multicolumn{10}{|l|}{ LDL-to-HDL ratio ( $\mathrm{mmol} / \mathrm{l})$} \\
\hline Exercise group & 56 & 1.57 & 0.55 & $1.45-1.74$ & 1.55 & 0.47 & $1.45-1.70$ & $\mathrm{~T}: 1.87$ & 0.17 \\
\hline Reduced hours group & 40 & 1.64 & 0.46 & $1.50-1.78$ & 1.56 & 0.48 & $1.39-1.67$ & $\mathrm{l}: 1.56$ & 0.21 \\
\hline Reference group & 59 & 1.68 & 0.56 & $1.53-1.82$ & 1.70 & 0.57 & $1.54-1.84$ & & \\
\hline \multicolumn{10}{|l|}{ Neuroendocrine markers } \\
\hline \multicolumn{10}{|l|}{ DHEAS (mmol/l) } \\
\hline Exercise group & 58 & 4.07 & 1.99 & $3.62-4.65$ & 4.05 & 2.06 & $3.57-4.67$ & $\mathrm{~T}: 0.54$ & 0.46 \\
\hline Reduced hours group & 37 & 3.69 & 1.81 & $3.32-4.59$ & 3.97 & 2.07 & $3.39-4.70$ & I: 2.28 & 0.11 \\
\hline Reference group & 61 & 3.89 & 2.36 & $3.27-4.46$ & 3.79 & 2.26 & $3.19-4.33$ & & \\
\hline \multicolumn{10}{|l|}{ Prolactin $(\mu \mathrm{g} / \mathrm{l})$} \\
\hline Exercise group & 58 & 8.67 & 4.55 & $7.52-16.5$ & 8.64 & 4.27 & $1.34-30.2$ & $\mathrm{~T}: 0.06$ & 0.81 \\
\hline Reduced hours group & 37 & 8.82 & 3.57 & $7.75-9.90$ & 8.89 & 4.57 & $4.44-27.5$ & I: 1.15 & 0.32 \\
\hline Reference group & 61 & 8.74 & 3.67 & $7.77-9.63$ & 9.59 & 4.82 & $8.29-10.7$ & & \\
\hline Metabolic measures & & & & & & & & & \\
\hline Glucose (mmol/l) & & & & & & & & & \\
\hline Exercise group & 57 & 5.08 & 0.48 & $4.95-5.24$ & 4.87 & 0.79 & $4.69-5.18$ & $\mathrm{~T}: 1.70$ & 0.19 \\
\hline Reduced hours group & 38 & 5.07 & 0.46 & $4.96-5.28$ & 5.00 & 0.50 & $4.78-5.64$ & I: 3.29 & 0.04 \\
\hline Reference group & 59 & 4.95 & 0.38 & $4.76-5.50$ & 5.02 & 0.60 & $4.82-5.55$ & & \\
\hline $\mathrm{HbA} 1 \mathrm{c}(\mathrm{mmol} / \mathrm{l})$ & & & & & & & & & \\
\hline Exercise group & 58 & 4.32 & 0.28 & $4.25-4.42$ & 4.26 & 0.32 & $4.18-4.42$ & $\mathrm{~T}: 5.04$ & 0.03 \\
\hline Reduced hours group & 38 & 4.39 & 0.28 & $4.25-4.82$ & 4.33 & 0.39 & $4.15-4.71$ & I: 0.24 & 0.79 \\
\hline Reference group & 59 & 4.35 & 0.29 & $4.26-4.57$ & 4.32 & 0.37 & $4.20-4.60$ & & \\
\hline Waist-to-hip ratio $(\mathrm{cm})$ & & & & & & & & & \\
\hline Exercise group & 58 & 0.80 & 0.07 & $0.79-0.83$ & 0.83 & 0.13 & $0.80-0.86$ & $\mathrm{~T}: 3.58$ & 0.06 \\
\hline Reduced hours group & 43 & 0.80 & 0.06 & $0.78-0.82$ & 0.85 & 0.09 & $0.83-0.88$ & I: 3.98 & 0.02 \\
\hline Reference group & 64 & 0.83 & 0.11 & $0.81-0.86$ & 0.82 & 0.06 & $0.80-0.83$ & & \\
\hline Cardiovascular measures & & & & & & & & & \\
\hline Systolic blood pressure & & & & & & & & & \\
\hline Exercise group & 58 & 118.2 & 21.0 & $112.5-123.2$ & 115.8 & 19.5 & $110.5-120.7$ & $\mathrm{~T}: 2.19$ & 0.14 \\
\hline Reduced hours group & 43 & 113.6 & 15.1 & $107.8-117.4$ & 113.0 & 16.27 & $106.5-116.2$ & I: 0.46 & 0.63 \\
\hline Reference group & 64 & 110.5 & 13.5 & $107.2-113.8$ & 109.7 & 13.3 & $106.3-112.8$ & & \\
\hline Diastolic blood pressure & & & & & & & & & \\
\hline Exercise group & 58 & 81.4 & 12.6 & $77.5-84.2$ & 79.8 & 12.0 & $76.1-82.4$ & $\mathrm{~T}: 2.62$ & 0.11 \\
\hline Reduced hours group & 43 & 79.5 & 11.0 & $74.8-81.6$ & 78.1 & 11.2 & $73.2-80.1$ & I: 0.16 & 0.86 \\
\hline Reference group & 64 & 76.8 & 10.9 & $74.1-79.4$ & 76.1 & 10.7 & $73.3-78.6$ & & \\
\hline Heart rate (beats/minute) & & & & & & & & & \\
\hline Exercise group & 58 & 63.7 & 7.90 & $61.6-65.6$ & 64.4 & 10.5 & $61.8-67.1$ & $\mathrm{~T}: 0.08$ & 0.78 \\
\hline Reduced hours group & 43 & 64.0 & 8.89 & $62.2-67.7$ & 63.4 & 6.62 & $62.8-67.5$ & I: 0.95 & 0.58 \\
\hline Reference group & 64 & 63.1 & 8.43 & $61.0-65.1$ & 63.4 & 8.86 & $61.2-65.6$ & & \\
\hline
\end{tabular}


Table 2. Descriptive statistics (means and standard deviations) and $95 \%$ confidence intervals (95\% $\mathrm{Cl}$ ) for the self-ratings on the selfrated measures for the two intervention groups and the reference group before, after 6 months, and after 12 months and results from the repeated analyses of variance, reporting time $(\mathrm{T})$ effects and interaction $(\mathrm{I})$ effects and exact P-values.

\begin{tabular}{|c|c|c|c|c|c|c|c|c|c|c|c|c|}
\hline \multirow[t]{2}{*}{ Self-rating } & \multirow[t]{2}{*}{$\mathrm{N}$} & \multicolumn{3}{|c|}{ Before } & \multicolumn{3}{|c|}{6 months } & \multicolumn{3}{|c|}{12 months } & \multirow[t]{2}{*}{ F-value } & \multirow[t]{2}{*}{ P-value } \\
\hline & & Mean & SD & $95 \% \mathrm{Cl}$ & Mean & SD & $95 \% \mathrm{Cl}$ & Mean & SD & $95 \% \mathrm{Cl}$ & & \\
\hline \multicolumn{13}{|l|}{ Self-rated health } \\
\hline Exercise group & 56 & 2.21 & 0.89 & $1.97-2.45$ & 2.20 & 0.92 & $1.95-2.44$ & 2.13 & 0.88 & $1.90-2.37$ & T: 0.24 & 0.78 \\
\hline Reduced hours group & 45 & 2.47 & 1.04 & $2.16-2.78$ & 2.49 & 0.89 & $2.22-2.76$ & 2.40 & 0.96 & $2.11-2.69$ & I: 0.45 & 0.48 \\
\hline Reference group & 57 & 2.39 & 0.82 & $2.17-2.60$ & 2.47 & 0.89 & $2.24-2.71$ & 2.49 & 0.95 & $2.34-2.74$ & & \\
\hline \multicolumn{13}{|l|}{ Lack of recovery } \\
\hline Exercise group & 56 & 2.29 & 0.74 & $1.55-2.17$ & 2.27 & 0.83 & $2.05-2.49$ & 2.19 & 0.74 & $1.99-2.39$ & $\mathrm{~T}: 1.29$ & 0.28 \\
\hline Reduced hours group & 45 & 2.52 & 0.81 & $2.28-2.76$ & 2.46 & 0.83 & $2.21-2.70$ & 2.40 & 0.91 & $2.12-2.67$ & I: 0.43 & 0.78 \\
\hline Reference group & 56 & 2.39 & 0.74 & $2.19-2.59$ & 2.40 & 0.71 & $2.21-2.59$ & 2.39 & 0.78 & $2.18-2.60$ & & \\
\hline \multicolumn{13}{|l|}{ Fatigue } \\
\hline Exercise group & 57 & 3.12 & 0.76 & $2.92-3.32$ & 3.10 & 0.72 & $2.91-3.29$ & 3.05 & 0.73 & $2.86-3.25$ & $\mathrm{~T}: 0.64$ & 0.53 \\
\hline Reduced hours group & 46 & 3.40 & 0.69 & $3.19-3.60$ & 3.42 & 0.71 & $3.21-3.63$ & 3.39 & 0.70 & $3.18-3.59$ & I: 0.12 & 0.98 \\
\hline Reference & 58 & 3.25 & 0.72 & $3.06-3.44$ & 3.29 & 0.79 & $3.08-3.50$ & 3.22 & 0.80 & $3.01-3.44$ & & \\
\hline \multicolumn{13}{|l|}{ General symptoms } \\
\hline Exercise group & 56 & 4.00 & 2.00 & $3.40-4.54$ & 3.79 & 1.88 & $3.28-4.29$ & 3.75 & 1.80 & $3.27-4.23$ & $\mathrm{~T}: 1.08$ & 0.34 \\
\hline Reduced hours group & 45 & 3.67 & 2.03 & $3.06-4.29$ & 3.78 & 1.86 & $3.22-4.34$ & 3.82 & 2.09 & $3.19-4.45$ & I: 2.26 & 0.06 \\
\hline Reference group & 60 & 3.20 & 1.92 & $2.70-3.70$ & 3.88 & 1.96 & $3.38-4-39$ & 3.80 & 1.81 & $3.33-4.27$ & & \\
\hline \multicolumn{13}{|l|}{ Upper-extremity disorder } \\
\hline Exercise group & 58 & 1.93 & 0.93 & $1.69-2.18$ & 1.59 & 1.21 & $1.27-1.91$ & 1.64 & 1.12 & $1.34-1.93$ & $\mathrm{~T}: 1.07$ & 0.35 \\
\hline Reduced hours group & 43 & 1.86 & 1.01 & $1.55-2.17$ & 1.98 & 1.06 & $1.65-2.30$ & 1.93 & 1.14 & $1.58-2.28$ & I: 2.26 & 0.06 \\
\hline Reference group & 59 & 1.83 & 0.93 & $1.59-2.07$ & 1.90 & 0.94 & $1.65-2.14$ & 1.71 & 1.08 & $1.43-1.99$ & & \\
\hline \multicolumn{13}{|l|}{ Work-home interference } \\
\hline Exercise group & 57 & 4.46 & 2.58 & $3.77-5.14$ & 5.42 & 3.28 & $4.55-6.29$ & 5.36 & 3.26 & $4.49-6-23$ & $\mathrm{~T}: 1.00$ & 0.37 \\
\hline Reduced hours group & 45 & 5.09 & 3.24 & $4.12-6.06$ & 5.31 & 3.54 & $4.25-6.38$ & 5.11 & 3.59 & $4.03-6.19$ & $\mathrm{l}: 1.87$ & 0.12 \\
\hline Reference group & 59 & 5.53 & 3.22 & $4.69-6.36$ & 5.27 & 3.33 & $4.40-6.14$ & 5.03 & 3.24 & $4.19-5.88$ & & \\
\hline \multicolumn{13}{|l|}{ Work ability } \\
\hline Exercise group & 56 & 8.13 & 1.72 & $7.67-8.59$ & 8.32 & 1.72 & $7.86-8.78$ & 8.34 & 1.34 & $7.97-8.71$ & $\mathrm{~T}: 1.07$ & 0.35 \\
\hline Reduced hours group & 45 & 7.89 & 1.94 & $7.40-8.56$ & 8.31 & 1.54 & $7.85-8.77$ & 8.09 & 1.52 & $7.63-8.55$ & I: 3.35 & 0.01 \\
\hline Reference group & 59 & 8.49 & 1.42 & $8.12-8.86$ & 7.90 & 2.03 & $7.37-8.43$ & 7.59 & 2.27 & $7.80-8.18$ & & \\
\hline
\end{tabular}

A look at the posthoc analyses shows that the results with respect to health-related measures seemed to differ between the interventions. For the physical-exercise group, there were positive effects over time for glucose. There was also a trend suggesting effects on upper-extremity disorders. These positive effects emerged at the first follow-up, after 6 months, and were sustained or had further improved after 1 year (analyses not shown). The effect on glucose found in the physical-exercise group may be of importance for the prevention of health problems related to metabolism. In addition, the trend showing reduced upper-extremity disorders suggests that physical exercise may be related to important health improvements (34), when it is considered that women working in dentistry have a high prevalence of upper-extremity disorders $(20,35)$, although no firm conclusions can be drawn based on a trend alone. When it comes to the reduced workhours, the health benefits remain unclear. Although the increased HDL levels found in this group were positive for health and may be associated with anabolic, health-promoting bodily processes $(36$, $37)$, the simultaneous increases in total cholesterol and the lack of significant changes in the LDL-to-HDL ratio make it difficult to interpret these findings, particularly with the paralleling increase in the waist-to-hip ratio. Taken together, the findings concerning the effects of reduced workhours on biomarkers are not clearly related to changes that are known to prevent future health problems.

Changes also occurred among the referents in terms of increasing levels of physical activity and exercise. These changes may be a result of these women taking part in a study and undergoing repeated health checkups. However, apart from increasing levels of HDL, there were no positive effects. On the contrary, there were increased levels of total cholesterol, triglycerides, and decreased work ability among the referents.

An understanding of the ways in which reduced workhours may affect health is limited. Contrary to the hypothesis, the results did not support a reduction in work-home interference or improved recovery from work in the reduced-workhours group. However, there was an increase in physical activity and exercise, and, consequently, physical activity may account for some 
of the effect in the reduced-workhours group. However, the health benefits in the physical-exercise group was larger, and it seems reasonable to suggest that though reduced workhours may be beneficial when used for physical activity, the impact is greater when the physical exercise is mandatory.

\section{Studying a healthy population}

Although meta-analyses have suggested that the scientific evidence for worksite health-promotion programs can be summarized as indicative or acceptable (38), the resulting effect sizes are often small (7), as in our study, particularly for the self-ratings. A key factor explaining the small effect sizes in worksite interventions is that the participants are part of a healthy population and subsequently are fairly healthy at the start of the interventions. This is true in our study, in which the mean levels were within the normal range (tables 1 and 2), suggesting a ceiling effect for health improvements. Yet, from a public health perspective, a small effect on the individual level can still be important if the number of persons affected are great enough. However, instead of focusing on improvements in health, it may be more relevant to discuss whether an intervention reduces future health problems or improves health-related functioning. Such an approach was adopted in a previous study that showed that an intervention reduced the decline in work ability (2). A similar pattern emerged in our study, in which the reference group, but none of the intervention groups, reported reduced work ability during the study period. There was a trend towards a similar pattern for general symptoms; although caution is needed in interpreting trends. In all, this finding suggests that a lack of health-related improvements may be associated with health benefits anyway, when the intervention delays, or prevents, the negative effects found among referents. However, an overall decline in health is the most likely to happen over a longer period of time, implying that, in order to find such effects, longer follow-up periods would be needed.

\section{Limitations and strengths}

In this study, cluster rather than individual randomization was used. To minimize the effects of variations between clusters, the differences between participating workplaces were kept to a minimum (eg, from the same organization, doing the same type of work, and being financially equivalent), and the workplaces were matched before the randomization. Despite these procedures, differences between the workplaces may have influenced the effects of the intervention. However, randomization on an individual level is often impractical or impossible in worksite interventions. In addition, including all those working at one workplace in the same intervention has the advantage of increasing ecological validity and reducing the risk of contamination between interventions.

No additional employees were recruited to compensate for the reduction in workhours, but full services were still expected. This situation could potentially increase work demands and thereby reduce the beneficial effects of the interventions. However, a look at the effects of the interventions into self-rated work demands showed no changes in perceived work demands (results not shown). Importantly, the lack of additional employees during an intervention is a common real-life scenario, and it increases the ecological validity of the study.

Approximately half of the participating women were part-time workers. For them, the reduction in workhours, or time for physical exercise, was less than 2.5 hours. Since part-time work may be a coping strategy to handle work-home interference or other demands, part-time workers may differ from full-time employees both in terms of baseline health and in terms of time spent on an intervention (eg, hours of worktime reduction). However, the initial analyses showed no differences between the part-timers and full-timers, for either the baseline or outcome measures (results not shown). This lack of differences may be related to the modest differences in the time spent on the intervention in that, for most of the part-timers, the intervention involved 2 hours instead of 2.5 hours.

A homogeneous group of women employed in dentistry within the public health care sector participated in this study. This homogeneity reduces generalization to other groups of employed women working outside the public health care sector. However, restricting the study to a homogeneous group of women increased the power of the intervention and reduced the influence of confounders.

The number of dropouts was low throughout this study. Another strength of this research was the concurrent assessment of biomarkers and self-reports and the fact that these measurements were obtained before the intervention and 6 and 12 months after it. However, due to the well-known seasonal variations in biomarkers, only data from the baseline measurements and the 12month follow-up were analyzed. Of course, the sheer number of measurements and the many significance tests performed in the study increased the risk for significant effects by chance (39). Consequently, the interpretation of the findings should focus on the overall pattern in each group, rather than on individual measures. Nevertheless, the use of repeated measurements revealed some distinct group effects and made it possible to separate temporary effects from effects that were sustained over time. Yet additional follow-ups over longer periods of 
time may be needed to adequately map the preventive effects of an intervention.

\section{Concluding remarks}

Taken together, our study on women employed in dentistry shows that reduced workhours increased the levels of physical activity and exercise, resulting in positive effects on HDL. When it was mandatory to spend the reduced workhours on physical activity, the increase in physical exercise was even greater, and it was associated with positive effects on glucose and a trend suggesting effects on upper-extremity disorders. From this finding, it follows that interventions involving a modest reduction in workhours seem to be more effective when the time is spent on physical exercise.

\section{Acknowledgments}

We are indebted to all the employees who volunteered to participate in this study. We also thank the nurses at the occupational health company, AB Previa, who carried out the health checkups.

This research was supported by grants to Ulf Lundberg from the Bank of Sweden Tercentenary Foundation and the Swedish Council for Working Life and Social Research and to Petra Lindfors from the Anna Ahlström and Ellen Terserus Foundation and from the University of Stockholm.

\section{References}

1. Titze S, Martin BW, Seiler R, Stronegger W, Marti B. Effects of a lifestyle physical activity intervention on stages of change and energy expenditure in sedentary employees. Psychol Sport Exerc. 2001;2(2):103-16.

2. Pohjonen T, Ranta R. Effects of worksite physical exercise intervention on physical fitness, perceived health status, and work ability among home care workers: five-year follow-up. Prev Med. 2001;32(6):465-75.

3. Sjögren T, Nissinen KJ, Järvenpää SK, Ojanen MT, Vanharanta $\mathrm{H}$, Mälkiä EA. Effects of a workplace physical exercise intervention on the intensity of headache and neck and shoulder symptoms and upper extremity muscular strength of office workers: a cluster randomized controlled cross-over trial. Pain. 2005;116(1-2):119-28.

4. Proper KI, Koning M, van der Beek AJ, Hildebrandt VH, Bosscher RJ, van Mechelen W. The effectiveness of worksite physical activity programs on physical activity, physical fitness, and health. Clin J Sport Med. 2003;13(2):106-17.

5. Sjögren T, Nissinen KJ, Järvenpää SK, Ojanen MT, Vanharanta $\mathrm{H}$, Mälkiä EA. Effects of a physical exercise intervention on subjective physical well-being, psychosocial functioning and general well-being among office workers: a cluster random- ized-controlled cross-over design. Scand J Med Sci Sports. 2006;16(6):381-90.

6. Wilson MG, Holman PB, Hammock A. A comprehensive review of the effects of worksite health promotion on healthrelated outcomes. Am J Health Promot. 1996;10(6):429-35.

7. Dishman RK, Oldenburg B, O’Neal H, Shephard RJ. Worksite physical activity interventions. Am J Prev Med. 1998;15(4):344-61.

8. Anttila T, Nätti J, Väisänen M. The experiments of reduced working hours in Finland. Community Work Fam. 2005;8(2):187-209.

9. Brynja O, Bildt C. Arbetstidsförkortning och hälsa: en litteraturgenomgång av befintlig forskning [Reduced working hours and health: a literature review of existing studies]. Stockholm: Arbetslivsinstitutet, förlagstjänst; 2005. Arbetslivsrapport 2005:11.

10. Wergeland EL, Veiersted B, Ingre M, Olsson B, Åkerstedt T, Bjørnskau T, et al. A shorter workday as a means of reducing the occurrence of musculoskeletal disorders. Scand J Work Environ Health. 2003;29(1):27-34.

11. Akerstedt T, Olsson B, Ingre M, Holmgren M, Kecklund G. A 6-hour working day-effects on health and well-being. J Hum Ergol (Tokyo). 2001;30(1-2):197-202.

12. Malmberg J, Byrgren M, Hansson M. Kartläggning av arbetstidsförkortningar 2000-2003 [Review of reduced working hours]. Stockholm: Arbetslivsinstitutet; 2003. Arbetslivsrapport 2003:15.

13. Bildt C. Arbetstidsförkortning och hälsa: försök med sex timmars arbetsdag inom offentlig sector [Reduced working hours and health: six hour workday withing the public sector]. Stockholm: National Institute for Working Life; 2007.

14. Janer G, Sala M, Kogevinas M. Health promotion trials at worksites and risk factors for cancer [review]. Scand J Work Environ Health. 2002;28(3):141-57.

15. Wanzel RS. Decades of worksite fitness programmes. progress or rhetoric? Sports Med. 1994;17(5):324-37.

16. Marshall AL. Challenges and opportunities for promoting physical activity in the workplace. J Sci Med Sport. 2004;7(1 Suppl):60-6.

17. Shephard RJ. Worksite fitness and exercise programs: a review of methodology and health impact. Am J Health Promot. 1996;10(6):436-52.

18. Ilmarinen J, Tuomi K, Klockars M. Changes in the work ability of active employees over an 11-year period. Scand J Work Environ Health. 1997;23 suppl 1:49-57.

19. Tuomi K, Luostarinen T, Ilmarinen J, Klockars M. Work load and individual factors affecting work disability among aging municipal employees. Scand J Work Environ Health. 1991;17 suppl 1:94-8.

20. Lindfors $P$, von Thiele U, Lundberg U. Work characteristics and upper extremity disorders in female dental health workers. J Occup Health. 2006;48(3):192-7.

21. Taris TW, Kompier M. Challenges in longitudinal designs in occupational health psychology [review]. Scand J Work Environ Health. 2003;29(1):1-4.

22. Ockene IS, Chiriboga DE, Stanek EJ III, Harmatz MG, Nicolosi R, Saperia G, et al. Seasonal variation in serum cholesterol levels: treatment implications and possible mechanisms. Arch Intern Med. 2004;164(8):863-70.

23. Garde AH, Hansen AM, Skovgaard LT, Christensen JM. Seasonal and biological variation of blood concentrations of total cholesterol, dehydroepiandrosterone sulfate, hemoglobin A1c, $\operatorname{IgA}$, prolactin, and free testosterone in healthy women. Clin Chem. 2000;46(4):551-9. 
24. Imai Y, Munakata M, Tsuji I, Ohkubo T, Satoh H, Yoshino $\mathrm{H}$, Watanabe N, et al. Seasonal variation in blood pressure in normotensive women studied by home measurements. Clin Sci (London). 1996;90(1):55-60.

25. van Anders SM, Hampson E, Watson NV. Seasonality, waistto-hip ratio, and salivary testosterone. Psychoneuroendocrinology. 2006;31(7):895-9.

26. Jansson E. Allmäna rekommendationer om fysisk aktivitet [General recommendations for physical activity]. Sandviken (Sweden): Statens Folkhälsoinstitut; 2003. Report 2003:44.

27. von Thiele U, Lindfors P, Lundberg U. Self-rated recovery from work stress and allostatic load in women. J Psychosom Res. 2006;61(2):237-42.

28. Gustafsson K, Lindfors P, Aronsson G, Lundberg U. Validering av frågor avseende nedvarvning och återhämtning-samband mellan salivkortisol och självskattningar [Validation of questions on recovery-relationships between salivary cortisol and self-ratings of recovery]. Stockholm: Arbetslivsinstitutet; 2006. Arbete Hälsa 7.

29. Frone MR, Russell M, Cooper ML. Antecedents and outcomes of work-family conflict: testing a model of the work-family interface. J Appl Psychol. 1992;77(1):65-78.

30. Eriksson I, Unden AL, Elofsson S. Self-rated health. comparisons between three different measures: results from a population study. Int J Epidemiol. 2001;30:326-33.

31. Tuomi K, Ilmarinen J, Jahkola A, Katajarinne L, Tulkki A. Work ability index. Helsinki: Finnish Institute of Occupational Health; 1998.
32. Dallner M, Elo A, Gamberale F, Hottinen V, Knardahl S, Lindström K, et al. Validation of the general Nordic questionnaire (QPSNordic) for psychological and social factors at work. Copenhagen: Nordiska ministerrådet; 2000.

33. Kuorinka I, Jonsson B, Kilbom Å, Vinterberg H, Biering-Sörensen F, Andersson G, et al. Standardised Nordic questionnaires for the analysis of musculoskeletal symptoms. Appl Ergon. 1987;18(3):233-7.

34. Lundberg U. Psychophysiology of work: stress, gender, endocrine response, and work-related upper extremity disorders. Am J Ind Med. 2002;41(5):383-92.

35. Statistiska Centralbyrån (SCB). Statistisk årsbok för sverige 2005, vol 91 [Statistical yearbook of Sweden, vol 91]. Stockholm: Sveriges officiella statistik, SCB; 2005.

36. McEwen BS. The neurobiology of stress: from serendipity to clinical relevance. Brain Res. 2000;886(1-2):172-89.

37. McEwen BS, Seeman T. Protective and damaging effects of mediators of stress: elaborating and testing the concepts of allostasis and allostatic load. Ann N Y Acad Sci. 1999;896:3047.

38. Heaney CA, Goetzel RZ. A review of health-related outcomes of multi-component worksite health promotion programs. Am J Health Promot. 1997;11(4):290-307.

39. Cohen J. Things I have learned (so far). Am Psychol. 1990;45(12):1304-12.

Received for publication: 14 June 2007 